\title{
Transcriptional profiling analysis of Penicillium digitatum, the causal agent of citrus green mold, unravels an inhibited ergosterol biosynthesis pathway in response to citral
}

\author{
Qiuli OuYang, Nengguo Tao* and Guoxing Jing
}

\begin{abstract}
Background: Green mold caused by Penicillium digitatum is the most damaging postharvest diseases of citrus fruit. Previously, we have observed that citral dose-dependently inhibited the mycelial growth of $P$. digitatum, with the minimum inhibitory concentration (MIC) of $1.78 \mathrm{mg} / \mathrm{mL}$, but the underlying molecular mechanism is barely understood.

Results: In this study, the transcriptional profiling of the control and 1/2MIC-citral treated P. digitatum mycelia after 30 min of exposure were analyzed by RNA-Seq. A total of 6355 genes, including 2322 up-regulated and 4033 down-regulated genes, were found to be responsive to citral. These genes were mapped to 155 KEGG pathways, mainly concerning mRNA surveillance, RNA polymerase, RNA transport, aminoacyl-tRNA biosynthesis, ABC transporter, glycolysis/gluconeogenesis, citrate cycle, oxidative phosphorylation, sulfur metabolism, nitrogen metabolism, inositol phosphate metabolism, fatty acid biosynthesis, unsaturated fatty acids biosynthesis, fatty acid metabolism, and steroid biosynthesis. Particularly, citral exposure affected the expression levels of five ergosterol biosynthetic genes (e.g. ERG7, ERG11, ERG6, ERG3 and ERG5), which corresponds well with the GC-MS results, the reduction in ergosterol content, and accumulation of massive lanosterol. In addition, ERG11, the gene responsible for lanosterol 14a-demethylase, was observed to be the key down-regulated gene in response to citral.
\end{abstract}

Conclusion: Our present finding suggests that citral could exhibit its antifungal activity against $P$. digitatum by the down-regulation of ergosterol biosynthesis.

Keywords: Citral, Penicillium digitatum, RNA-Seq, Ergosterol biosynthesis

\section{Background}

Significant losses can occur after harvest during storage and marketing of citrus fruit primarily due to green mold, caused by Penicillium digitatum, and secondarily by blue mold and sour rot caused by $P$. italicum and Geotrichum citri-aurantii, respectively [1]. Among them, $P$. digitatum is the most economically devastating pathogen causing about $90 \%$ of the total loss of postharvest citrus fruit [2]. Currently, the control of

\footnotetext{
* Correspondence: nengguotao@126.com

School of Chemical Engineering, Xiangtan University, Xiangtan 411105, People's Republic of China
}

postharvest pathogens depends mainly on synthetic application, but extensive use of synthetic mmediate areas of research focus $[3,4]$.

, one of the volatile constituents in plant essentia has been demonstrated to have strong antifungal gainst $P$. digitatum, $P$. italicum, and G. citrior $150 \mathrm{~mL} / \mathrm{L}$ in absorbent pads) in a closed system, following application of conidia $\left(20 \mu \mathrm{L}\right.$ of $10^{6}$ conidia/mL) to 
puncture wounds, delayed the onset of sour rot at room temperature by $7-10$ days and at $5{ }^{\circ} \mathrm{C}$, by $13-30$ days [4]. Previously, we have observed that citral inhibited the myclial growths of $P$. italicum and G. citri-aurantii in a dose dependent manner [7, 8], and the application of wax enriched with citral significantly decreased the incidence of green mold after 6 days of storage at $25 \pm 2{ }^{\circ} \mathrm{C}$ [9]. Therefore, it might be an alternative as fungicide in controlling postharvest diseases in citrus fruit.

The antifungal mechanism of volatile compounds has been attributed to its capacity to disturb the cellular membrane, interfere with the cellular metabolism, react with active sites of enzymes, or act as $\mathrm{H}^{+}$carriers $[10,11]$. In our previous studies, citral was found to destroy the membrane permeability and integrity of $P$. italicum and G. citri-aurantii by causing significant losses in total lipids or ergosterol contents [7, 8]. In addition, citral at a minimum inhibitory concentration (MIC, $1.78 \mathrm{mg} / \mathrm{mL}$ ) evidently altered the mitochondrial morphology and inhibited the citrate cycle (TCA cycle) of $P$. digitatum [12]. However, information about the inhibitory mechanism of citral on $P$. digitatum at molecular level is rather limited, and thus, requires further studies.

Recently, numerous reports regarding the global gene expression in response to essential oils or their volatile components in fungal have been conducted. Parveen et al. [13] found that the cell wall- and membrane-related genes were major targets of $\alpha$-terpinene against Saccharomyces cerevisiae, showing that genes associated with protein analysis, carbohydrate metabolism, and transcription were repressed, whereas genes involved in ergosterol biosynthesis, phospholipid biosynthesis, cell wall organization and detoxification were activated. Rao et al. [14] reported that carvacrol can stimulate the expression levels of genes involved in alternate metabolic and energy pathways, stress response, autophagy, drug efflux, but repress genes mediating ribosome biogenesis and RNA metabolism. A microarray analysis revealed that $1 \%(\mathrm{v} / \mathrm{v}) p$-anisaldehyde can induce the expression levels of genes related to sulphur assimilation, aromatic aldehydes metabolism, and secondary metabolism in S. cerevisiae, suggesting that the normal metabolism of aromatic aldehydes was influenced [15]. In another report, $90 \mathrm{~min}$ of exposure to $128 \mu \mathrm{g} / \mathrm{mL}$ thymol resulted in a reduction in intracellular thiamine concentration in yeast by impairing thiamin metabolism. In contrast, many genes involving in maintaining cell membrane and cell wall integrity, sulfur assimilation, methionine biosynthesis, and production of AdoMET were drastically induced [16]. These findings provide some novel clues for the understanding of the antifungal mechanism of plant essential oils.

RNA-Seq is an increasingly attractive method for whole-genome expression studies in many biological systems. As compared with traditional microarrays, despite their instrumental role in profiling the global expression of genes, this technique extends the possibilities of transcriptome studies to the analysis of previously unidentified genes and splice variants due to the advantages such as no need to provide a referenced genomic sequence, a fully coverage of three types of RNA, an unlimited dynamic range of quantification at reduced technical variability, the declining cost of sequencing, and so on $[17,18]$. It has been widely used to unravel the pathogenetic mechanisms or diseases control in citrus fruit [19-21]. Therefore, our present study is to analyze the global gene expression profiles in P. digitatum mycelia with or without citral treatment by RNA-Seq, in an effort to explore the underlying molecular mechanism and to find some key metabolic pathways or genes involved in.

\section{Methods}

\section{Fungal cultivation}

$P$. digitatum was isolated from infected citrus fruit and preserved on potato dextrose agar (PDA) at $25 \pm 2{ }^{\circ} \mathrm{C}$. Two hundred micro liter fungal suspensions $\left(5 \times 10^{5} \mathrm{cfu} /\right.$ $\mathrm{mL}$ ) were added to $40 \mathrm{~mL}$ potato dextrose broth (PDB) and incubated in a moist chamber at $28 \pm 2{ }^{\circ} \mathrm{C}$ for $72 \mathrm{~h}$. The mycelia were vacuum-filtered and weighted at a $6 \mathrm{~h}$ interval to make a growth curve.

Based on the result of growth curve, $1 \mathrm{~g}$ wet mycelia in logarithmic metaphase ( $48 \mathrm{~h}$ of culture) were added to $20 \mathrm{~mL}$ PBS (pH 6.8) and incubated with 1/2MIC (half of minimum inhibitory concentration; $0.89 \mathrm{mg} / \mathrm{mL}$ ) or MIC of citral for 0, 30, 60, and 120 min. Samples without citral were severed as a control. The resulting mycelia were vacuum-filtered, weighted, and recorded to select optimal concentration and time for the next analysis. All collected $P$. digitatum mycelia were grinded to powders in liquid nitrogen and stored at $-80{ }^{\circ} \mathrm{C}$ until further use.

\section{RNA isolation, integrity examination and RNA-Seq library preparation}

Total RNAs from control, 1/2 MIC or MIC citraltreated samples after 30 min of exposure were extracted with TRIzol regent (Invitrogen, USA) according to the manufacturer's instruction and treated with RNase-free DNase I (Takara Biotechnology, China). RNA integrity was determined by a 2100 bioanalyzer (Agilent, USA). Poly (A) mRNA from control and 1/2MIC citral-treated samples, designated as CK30 and T30, respectively, was isolated with oligo-dT beads and then treated with the fragmentation buffer. The cleaved RNA fragments were then transcribed into first-strand cDNA using reverse transcriptase and random hexamer primers, followed by second strand cDNA synthesis using DNA polymerase I and $\mathrm{RNaseH}$. The double stranded cDNA was further subjected to end-repair using T4 DNA polymerase, 
Klenow fragment, and T4 Polynucleotide kinase, followed by a single A base addition using Klenow 3' to $5^{\prime}$ exo-polymerase. It was then ligated with adapter or index adapter using T4 quick DNA ligase. Adaptor ligated fragments were selected according to the size and the desired range of cDNA fragments were excised from the gel. PCR was performed to selectively enrich and amplify the fragments. Finally, after validating on an Agilent 2100 Bioanalyzer and ABI StepOnePlus RealTime PCR System, the cDNA library was sequenced on a flow cell using Illumina HiSeq2000 ${ }^{\mathrm{Tm}}$ [22].

\section{Assembly and functional annotation}

Transcriptome de novo assembly of the short reads was carried out using Trinty software [23]. After filtration of the low quality reads, clean reads were randomly clipped into 25-bp k-mers and assembled using de Bruijin graph and Trinty software. Furthermore, the reads producing large fragment without $\mathrm{N}$ is named contig and the result sequences of trinity is called unigenes. Then unigenes were clustered using TGI Clustering tools to obtain the finally unigenes [24]. Finally, blastx alignment $(e$ value $<0.00001$ ) between unigenes and protein databases (non-redundant protein (NR), Swiss-Prot, Kyoto Encyclopedia of Genes and Genomes (KEGG) and the Clusters of Orthologous Groups of proteins (COG)) were performed, and the best aligning results were selected as a priority order of NR, Swiss-Prot, KEGG and COG to determine the sequence orientation. When a unigene was not aligned to the above databases, ESTScan software [25] was used to predict its coding regions and to determine its sequence orientation. Gene ontology (GO) terms annotations of unigenes were performed with the Blast2GO program according to the NR annotation. The COG and KEGG pathway annotations were analyzed using Blastall software against the cluster of orthologous groups' database and the kyoto encyclopedia of genes and genomes database.

\section{Differential expression of unigenes}

The expression level of unigene is calculated by Fragments Per kb per Million reads (FPKM) method described by Audic and Claverie [26]. An expressed equally between two samples was calculated with the following formula:

$$
p(i \mid x)=\left(\frac{N_{2}}{N_{1}}\right)^{i} \frac{(x+i) !}{x ! i !\left(1+\frac{N_{2}}{N_{1}}\right)^{(x+i+1)}}
$$

Where, $\mathrm{N}_{1}$ is the total fragments number of the CK30, and $\mathrm{N}_{2}$ is total fragments number of T30; gene A holds $\mathrm{x}$ fragments in CK30 and $\mathrm{i}$ fragments in T30. The larger difference of the expression level between the CK30 and T30 is calculated with FDR $\leq 0.001$ and $\log _{2}$ Ratio $\geq 1$.
GO annotation and pathway analysis of differentially expressed genes (DEGs)

First, mapping all DEGs to each term of gene ontology database and calculating the gene numbers for each GO term has to get a gene list and gene numbers for every certain GO term, then using hypergeometric test to find significantly enriched GO terms in DEGs comparing to the genome background. The $P$ value calculating formula in this hypothesis test is.

$$
P=1-\sum_{i=0^{m-1}} \frac{\left(\begin{array}{c}
M \\
i
\end{array}\right)\left(\begin{array}{c}
N-M \\
n-i
\end{array}\right)}{\left(\begin{array}{c}
N \\
n
\end{array}\right)}
$$

Where, in GO analysis, $\mathrm{N}$ is the number of all genes with GO annotation; $n$ is the number of DEGs in N; M is the number of all genes that are annotated to the certain GO terms; $m$ is the number of DEGs in M. The calculated $p$ value goes through Bonferroni Correction, taking corrected- $P$ value $\leq 0.05$ as a threshold. In KEGG analysis, $\mathrm{N}$ is the number of all genes with KEGG annotation, $\mathrm{n}$ is the number of DEGs in N, M is the number of all genes annotated to specific pathways, and $\mathrm{m}$ is number of DEGs in $\mathrm{M}$.

\section{Real-time Fluorescence Quantitative PCR (RTFQ-PCR) analysis}

RNA was extracted from $P$. digitatum cells exposure to citral at various concentrations ( 0 and $1 / 2 \mathrm{MIC}$ ) for 0 , 30, 60, and 120 min using the Trizol reagent (Invitrogen, USA) following the manufacturer's instructions. Two micrograms of DNA-free RNA were used for reverse transcription by M-MLV (Promega, USA) with oligo dT18. RTFQ-PCR was performed on a BIO-RAD CFX Connect Thermal Cycler using FastStart Universal SYBR Green Master (Roche, Switzerland). All primer pairs for expression assays are listed in Table 1. RTFQ-PCR was programmed as follows: $95{ }^{\circ} \mathrm{C}$ for $10 \mathrm{~min}$ followed by 40 cycles of $95{ }^{\circ} \mathrm{C}$ for $15 \mathrm{~s}, 60{ }^{\circ} \mathrm{C}$ for $1 \mathrm{~min}$. The $2^{-\Delta \Delta \mathrm{CT}}$ method was used to quantify the value of every sample using actin gene as an internal reference [27].

\section{Sterols compositions by gas chromatography-mass spec- trometry (GC-MS)}

The sterols compositions of $P$. digitatum cells exposure to citral at a concentration of $1 / 2 \mathrm{MIC}$ for $0,30,60$, and $120 \mathrm{~min}$ were determined by GC-MS method [28, 29] with some modifications. The 2-day-old mycelia from $50 \mathrm{~mL}$ PDB were collected and centrifuged at $4000 \mathrm{~g}$ for $15 \mathrm{~min}$. Then the samples were dried with a vacuum freeze drier for $4 \mathrm{~h}$. About $0.5 \mathrm{~g}$ of dry mycelia were homogenized with liquid nitrogen and were suspended in $4 \mathrm{~mL}$ of freshly prepared $25 \%(\mathrm{w} / \mathrm{v}) \mathrm{NaOH}$ and $8 \mathrm{~mL}$ 
Table 1 Primer pair sequences designed for validation of differentially expressed genes in CK30 and T30 treatment P. digitatum using Real-time Fluorescence Quantitative PCR (RTFQ-PCR)

\begin{tabular}{lll}
\hline Gene ID & Gene name & Primer sequence (5'-3', forward/reverse) \\
\hline Unigene6144 & Actin & TGCGCTGAACCGAACTGCCG \\
Unigene8313 & TCGGGAGCTCGAAGCGCTC \\
Unigene8539 & & GCGCTGGCGATTGGTCGATG \\
& ERG11 & CAGGCCCAGTTCCGGGCTCC \\
Unigene6797 & ERG6 & CCATCGACCTCGTCCCCGCC \\
& & TCGCGCTTGCGGTITGGGG \\
Unigene5828 & ERG3 & CGCGTGATGCCGCCTTCAAC \\
Unigene8125 & & TGAGCCTTGCGGGCCTCACG \\
& CRG5 & CAGGCCATGGCCGCAATGCC \\
\hline
\end{tabular}

of absolute ethanol, vortexed for $30 \mathrm{sec}$ and sonicated for $10 \mathrm{~min}$, and then saponified at $80{ }^{\circ} \mathrm{C}$ for $1 \mathrm{~h}$. The mixtures were extracted with $2 \mathrm{~mL}$ petroleum ether for three times and washed by saturated $\mathrm{NaCl}$ solution twice. The organic upper layer was transferred into a new $10.0 \mathrm{~mL}$ plastic microcentrifuge safe-lock tube containing $40 \pm 2 \mathrm{mg}$ anhydrous sodium sulphate. The samples were then vacuum concentrated. Each residue was dissolved in $950 \mu \mathrm{L}$ of methyl tert-butyl ether and $50 \mu \mathrm{L}$ of silylation reagent mixture $\mathrm{N}$-methyl$\mathrm{N}$-trimethylsilyltrifluoroacetamide (MSTFA) and Ntrimethylsilylimidazole (TSIM) (9:1) was added. The samples were gently shaken and stored for completion of the silylation reaction at room temperature for at least $30 \mathrm{~min}$, before being subjected to GC-MS analysis. The samples without citral treatment were used as a control.

The analytical GC was carried out on a Shimadzu QP2010 plus gas chromatograph (Shimadzu, Kyoto, Japan) equipped with flame ionization detector (FID). A non-polar cross-linked fused-silica capillary column, HP-5MS (30 $\mathrm{m} \times 0.25 \mathrm{~mm} \times 0.25 \mu \mathrm{m}$; Agilent, Santa Clara, CA), was used. The oven temperature was held at $50{ }^{\circ} \mathrm{C}$ for $1 \mathrm{~min}$, programmed at a rate of $50{ }^{\circ} \mathrm{C} / \mathrm{min}$ to $260{ }^{\circ} \mathrm{C}$, then increased to $300{ }^{\circ} \mathrm{C}$ at a rate of $4{ }^{\circ} \mathrm{C} / \mathrm{min}$ where it remained for $10 \mathrm{~min}$. The carrier gas was helium $(1.3 \mathrm{~mL} / \mathrm{min})$. The injector temperature was $250{ }^{\circ} \mathrm{C}$, detector temperature $310{ }^{\circ} \mathrm{C}$ and the volume injected was $2 \mu \mathrm{L}$. MS analysis was carried out on the same chromatograph equipped with a Shimadzu QP 2010 GC/MS system, ionisation voltage $70 \mathrm{eV}$, ion source temperature $200{ }^{\circ} \mathrm{C}$, mass range $\mathrm{m} / \mathrm{z} 50-700$, scanning interval $0.5 \mathrm{~s}$ and scanning speed $1000 \mathrm{amu} / \mathrm{s}$. The sterol TMS ethers were identified by comparison with commercial references, the NIST $^{\mathrm{TM}}$ database or data from literature.
Determination of total ergosterol and lanosterol contents Total ergosterol and lanosterol contents of $P$. digitatum cells exposure to citral at a concentration of $1 / 2 \mathrm{MIC}$ for $0,30,60$, and $120 \mathrm{~min}$ were determined by highperformance liquid chromatography (HPLC) as reported by our previous study [7], whereas the detected wavelength for lanosterol was set at $210 \mathrm{~nm}$. The samples without citral treatment were used as a control.

\section{Statistical analysis}

All data were expressed as the mean \pm SD by measuring three independent replicates. Analysis of variance using one-way ANOVA followed by Duncan's test was performed to test the significance of differences between means obtained among the treatments at the $5 \%$ level of significance using SPSS statistical software package release 16.0 (SPSS Inc., Chicago, IL, USA).

\section{Results and discussions}

The growth of $P$. digitatum

The growth curve of $P$. digitatum is shown in Fig. 1a. During the first $24 \mathrm{~h}$ of initial incubation, the growth of $P$. digitatum cells was slow and remained in the lag phase. Then $P$. digitatum cells visibly grew and reached the logarithmic phase at $60 \mathrm{~h}$ of incubation. Correspondingly, the mycelia of $P$. digitatum that grew for $48 \mathrm{~h}$, which was suggested to be in the logarithmic metaphase, were chosen for the next analysis.

To determine the effects of citral on the growth of $P$. digitatum, the wet weight of $P$. digitatum mycelia exposed to citral was determined. As shown in Fig. 1b, citral markedly inhibited the mycelial growth of $P$. digitatum during the whole period, whereas that of the control group remained stable. After $30 \mathrm{~min}$ of exposure, the wet weight of $1 / 2 \mathrm{MIC}$ and MIC mycelia were $0.83 \pm 0.03 \mathrm{~g}$ and $0.71 \pm 0.06 \mathrm{~g}$, respectively, which were 


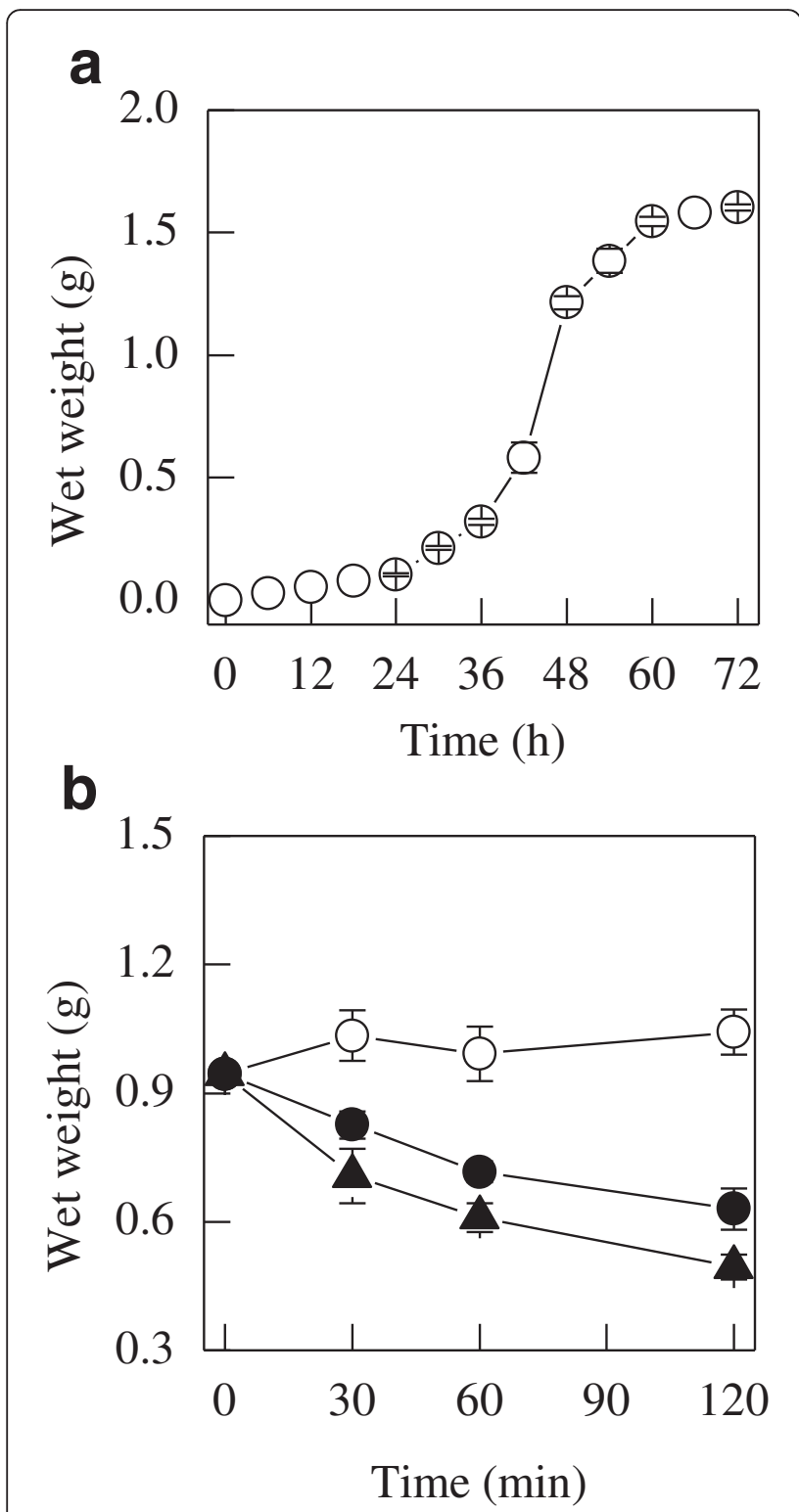

Fig. 1 a The growth curve of $P$. digitatum mycelia; $\mathbf{b}$ The wet weight of $P$. digitatum mycelia exposed to citral, (o) CK; $(\bullet)$ 1/2MIC; ( $\Delta$ ) MIC. Values are the mean \pm SD of three measurements

significantly lower than that of the control $(0.99 \pm 0.06 \mathrm{~g}$, $P<0.05)$. This inhibition was more obvious with the prolonging of the culture time. Considering that a RNA integrated number (RIN) value higher than 6.5 was the prerequisite for the RNA-Seq analysis, we further determined the RIN values in citral-treated or control samples at $30 \mathrm{~min}$ incubation. Results showed that the RIN values in $1 / 2 \mathrm{MIC}$ or MIC citral -treated and control groups were 6.7, 2.6, and 7.9, respectively (data not show), suggesting that MIC citral -treated samples were not suitable for further analysis. Therefore, only samples treated with $1 / 2 \mathrm{MIC}$ citral (T30) or without citral treatment (CK30) were chosen for RNA-Seq analysis.
Overall transcriptome profiles $P$. digitatum

To analyze the transcriptome profiles in CK30 and T30, a pooled cDNA sample from each strain was separately sequenced with the Illumina sequencing platform. The details in assembly and annotation information are shown in Table 2. After filtering the dirty raw reads, 25 and 27 million clean reads were obtained from CK30 and T30, respectively. Totally, 16898 unigenes were used for functional annotation and 14189 coding sequence (CDS) were mapped to the protein database or predicted (Additional file 1: Table S1 and Additional file 2: Table S2). Among them, 14235, 14555, 8584, 8714, 5832, and 9158 unigenes were annotated to NR, non-redundant nucleotide sequence (NT), Swiss-Prot, KEGG, COG, and GO database, respectively. The size distribution showed that the lengths of the CK30, T30, and all- unigenes were no more than 3000 nt (Fig. 2), and the distribution of unigenes was decreased with the increase of sequence size. The $300 \mathrm{nt}$ sequences were mostly distributed unigenes in CK30 and T30, followed by 200 or $400 \mathrm{nt}$, whereas only a few $3000 \mathrm{nt}$ sequences and no $200 \mathrm{nt}$ sequences were found. After searching in the National Center for Biotechnology Information (NCBI) nucleotide database by blastx using unigenes obtained from CK30 and T30, the major transcriptome profiles of $P$. digitatum were significantly matched to $P$. digitatum PHI26 (41.1 \%), P. digitatum Pd1 (40.2 \%), P. chrysogenum Wisconsin 54-1 (14.0\%), and other fungi (4.7 \%) (Fig. 3).

Based on functional annotation of unigenes, the predicted genes were further classified by Blast2GO analysis (Table 2) and 9158 unigenes from all-unigenes were categorized into 47 GO terms distributed into biological process, cellular component, and molecular function (Fig. 4). Clearly, the cellular process, metabolic process, and catalytic activity were the dominant categories. Genes involved in binding, cell, cell part, organelle, growth, multicellular organismal process, reproductive process, and receptor activity were found in those categories, while those related to biological adhesion, virion, virion part, cell killing, or locomotion were barely detected (Fig. 4). For the COG analysis, 5832 unigenes (Table 2) from all unigenes were categorized to 26 categories (Fig. 5). The most distributed one was the cluster of general function prediction (1744), followed by carbohydrate transport and metabolism (854), translation, ribosomal structure and biogenesis (765), and amino acid transport and metabolism (712).

A total of 16,898 all-unigenes were mapped to the referenced canonical pathways in KEGG, 8714 of them were annotated to 168 KEGG pathways. Among of which, 2550, 1087, and 898 unigenes were distributed to metabolic pathway, biosynthesis of secondary metabolites, and microbial metabolism in diverse environments, respectively. Few unigenes correlated with carotenoid biosynthesis (1 unigene), phosphotransferase system (PTS, 1 
Table 2 Summary data of reads in untreated strains (CK30) and citral-treated strains (T30) of P. digitatum mycelia transcriptomes

\begin{tabular}{lll}
\hline Parameters & CK30 & T30 \\
\hline Total clean reads & $25,722,906$ & $27,714,798$ \\
Total clean nucleotides (nt) & $2,315,067,540$ & $2,494,331,820$ \\
Q20 percentage & $97.61 \%$ & $97.45 \%$ \\
N percentage & $0.01 \%$ & $0.01 \%$ \\
GC percentage & $52.76 \%$ & $45.2 \%$ \\
Total number of contigs & 23,279 & 29,572 \\
Mean length of contigs (nt) & 612 & 471 \\
The number of unigenes & 17,877 & 20,711 \\
Mean length of unigenes (nt) & 859 & 688 \\
The number of all-unigenes & - & - \\
Mean length of unigenes & - & - \\
Unigenes annotation against NR & & 14,235 \\
Unigenes annotation against NT & & 14,555 \\
Unigenes annotation against Swiss-Prot & & 8,584 \\
Unigenes annotation against KEGG & & 8,714 \\
Unigenes annotation against COG & 5,832 \\
Unigenes annotation against GO & 9,158 \\
Up-regulated genes & & 2,322 \\
Down-regulated genes & 4,033 \\
\hline
\end{tabular}

unigene), and sesquiterpenoid and triterpenoid biosynthesis ( 2 unigenes) were also found.

\section{Differences in overall gene expressions and pathway between CK30 and T30}

The differences in gene expressions between CK30 and T30 were further analyzed (Additional file 3: Table S3). The variations of gene length and total reads distributions in gene expression levels were eliminated by FPKM calculation. The different gene expressions were calculated by false discovery rate $(F D R \leq 0.001)$ and the absolute value of $\log _{2}$ Ration $\geq 1$ as a threshold. A total of 6355 differential expression genes were detected between CK30 and T30, including 2322 up-regulated and 4033 downregulated genes (Table 2). The distribution of downregulated genes was nearly twice as that of up-regulated genes, which might be caused by the inhibition of $P$. digitatum mycelial growth.

A total of 3232 differentially expressed genes (DEGs) were mapped to the KEGG database and summed up to 155 pathways. The specific pathways associated with environmental information processing, such as $\mathrm{ABC}$ transport (64, $1.98 \%)$, MAPK signaling pathway (88, $2.72 \%)$, twocomponent system $(48,1.49 \%)$, phosphatidylinositol signaling system (22, $0.68 \%)$; the pathways belonged to cell membrane, such as fatty acid biosynthesis (28, $0.87 \%)$, biosynthesis of unsaturated fatty acids (14, $0.43 \%)$, steroid biosynthesis (20, $0.62 \%)$; the pathways involved in energy, such as nitrogen metabolism $(38,1.18 \%)$, oxidative phosphorylation (47, $1.45 \%)$, glycolysis/gluconeogenesis (64, $1.98 \%)$, and TCA cycle (21, $0.65 \%)$; the pathways related to genetic information, such as ribosome biogenesis in eukaryotes (78, $2.41 \%)$, RNA degradation (91, $2.82 \%)$, RNA polymerase $(24,0.74 \%)$, aminoacyl-tRNA biosynthesis $(29,0.9 \%)$ and ribosome $(33,1.02 \%)$, were all affected by citral treatment (Table 3 ).

\section{Genes related to stress response}

To survive from drastic environment changes, eukaryotes must rapidly adjust their gene expression programs to develop a series of protective mechanisms [30,31]. In this study, considerable alterations in gene expression levels related to cell rescue, defense, and detoxification were influenced by citral. Genes associated with the over-represented pathway, such as ribosome biogenesis in eukaryotes, mRNA surveillance pathway, RNA polymerase, RNA transport and aminoacyl-tRNA biosynthesis, were partially repressed, indicating a lesion in the translational activity of cells. This result, to a large extent, accounts for the low RIN value (2.6) in $P$. digitatum cells treated with MIC of citral for $30 \mathrm{~min}$. In addition, one gene responsible for mitochondrial ribosomal protein (MRPS5) was found to be down-regulated, indicating a blocking in mitochondrial translation and the loss of mitochondrial functions [32]. Correspondingly, a repression in energy-related pathways including 

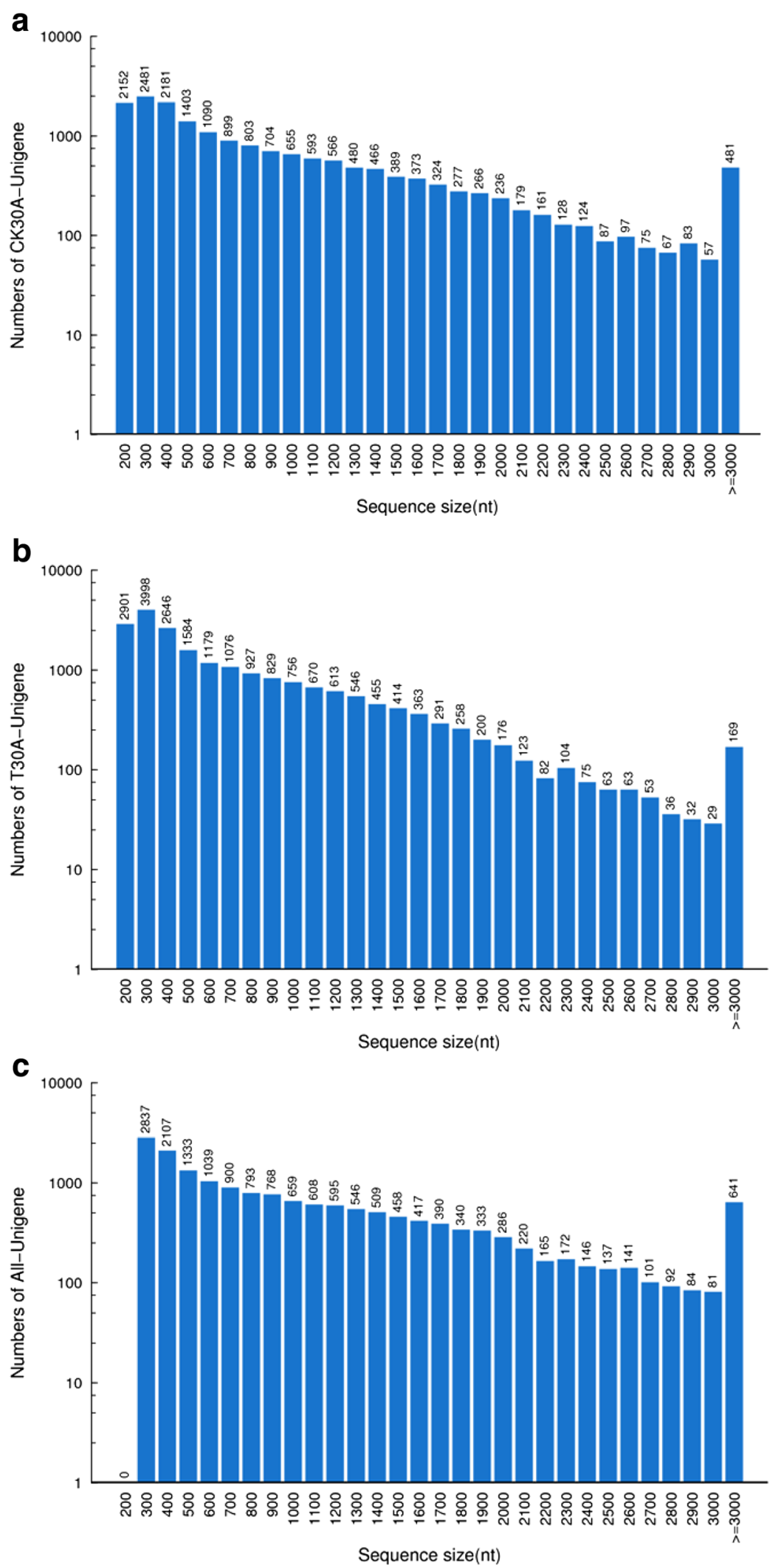

Fig. 2 The length distribution of unigenes after de novo assembly using the reads from CK30, T30, and CK30\&T30 samples, the horizontal coordinates are unigene lengths and the vertical coordinates are numbers of unigenes 


\section{(a) E-value Distribution}

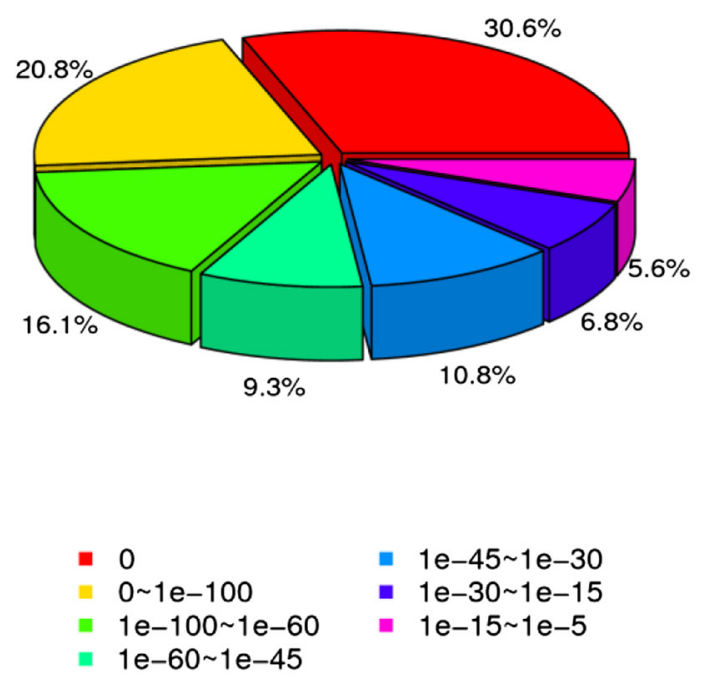

\section{(b) Similarity Distribution}

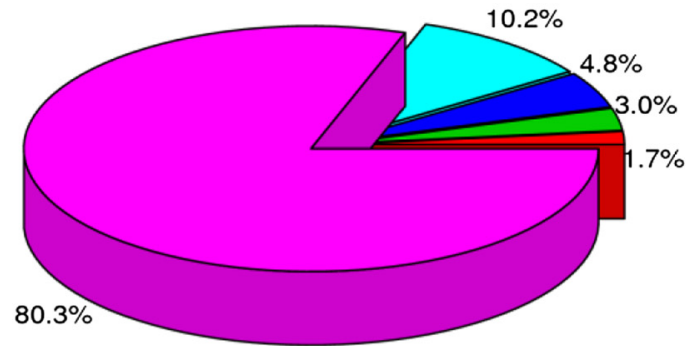

\section{(c) Species Distribution}

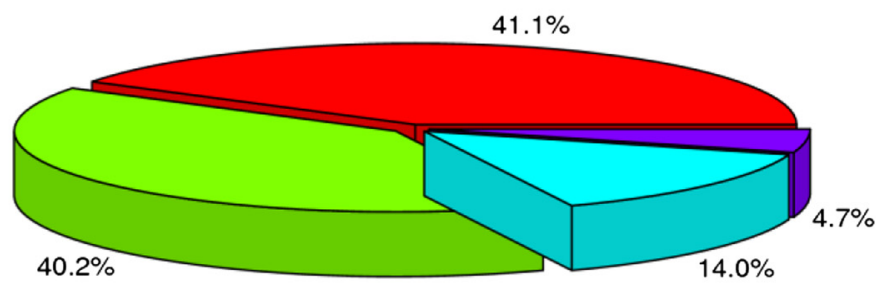

- Penicillium digitatum PHI26

- Penicillium digitatum Pd1

Inenicillium chrysogenum Wisconsin 54-1

- other

Fig. 3 Species distribution of the BLASTx matches (with an $E$-value $<10^{-5}$ ) to the unique transcripts against the non-redundant protein database. a The E-value distribution of NR annotation result; $\mathbf{b}$ The similarity distribution of NR annotation result; $\mathbf{c}$ The species distribution of NR annotation result

TCA cycle, glycolysis/gluconeogenesis, oxidative phosphorylation, sulfur metabolism, and nitrogen metabolism, was also observed. Most genes in these pathways, such as $S D H 1, f r d A, C S, I D H 1, H K, P F K, P K, f b c H$, ATPeF1G, ATPeVOC, cysQ, cysJ, aspA, nasB, and $g \ln A$, were down-regulated. Previously, we have demonstrated that citral treatment could evidently alter the mitochondrial morphology, reduce the ATP content and inhibit the TCA cycle of $P$. digitatum [12]. These results supported the hypothesis that the down-regulation of energy-demanding processes is a very important approach to help the cells escaping from energy crisis under extreme environmental conditions [33]. Interestingly, significant changes in genes involved in the environmental stress response were also observed, which was consistent with a previous report describing the global gene expressions in S. cerevisiae cells treated with thymol [16].

\section{Genes involved in multidrug resistance}

The typical gene subfamilies involved in multidrug resistance in fungal, such as multi-drug resistance (MRD, $\mathrm{ABCB}$ subfamily), multi-drug resistance-associated protein (MRP, ABCC subfamily), and pleiotropic drug resistance (PDR, ABCG subfamily), were affected by citral. A slight increase in the MRD gene PMR1 expression was observed in samples exposed to citral. This gene was an important determinant of resistance to demethylation inhibitor-resistant strains, which is normally suggested to 


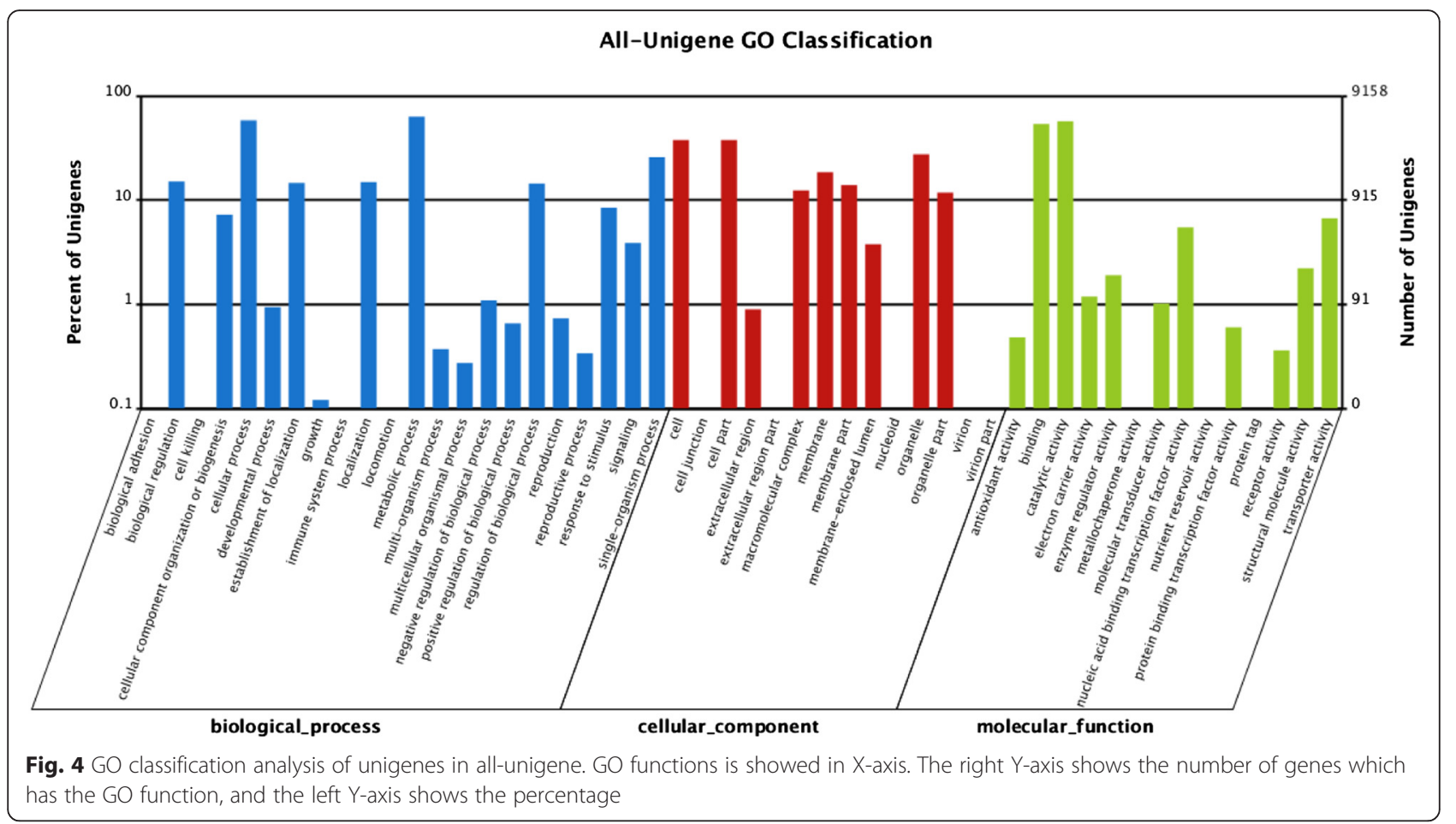

protect the cells against triflumizole [34]. Genes belonged to plasma membrane ATP-binding cassette (ABC) transporters, such as PDR5 and SNQ2, were also up-regulated. These two genes were involved in a robust induction of drug efflux mechanisms, and their expression levels in $S$. cerevisiae cells have been demonstrated to be strongly induced by thymol [16]. Interestingly, the expression levels of five MRP genes including MRP1, MRP4, MRP5, MRP7, and $M R P 13$, were down-regulated. This type of genes generally transports xenobiotic compounds or toxic metabolites that conjugated to glutathione, glucuronide, or sulfur, and the over-expression of $M R P 1$ gene can enhance the multidrug resistance in eukaryotic cells [35]. Therefore, the decrease in expression levels of MRP genes suggested that the multidrug resistance in $P$. digitatum cell might be impaired by citral.

\section{Genes associated with cell integrity}

Several targets including cell wall, cell membrane, mitochondrion, and genetic material, have been proposed to account for the antifungal activity of essential oils or their volatile compositions [3, 12-16, 36]. The cell wall is an extracellular layer outside the cell membrane which protects the cell against mechanical damage, osmotic strength and determines the cell shape. We found that several pathways associated with cell wall biogenesis, such as amino sugar and nucleotide sugar metabolism, starch and sucrose metabolism, were drastically influenced by citral. CHI1, Fks1, two important cell wall-related genes encoding for chitin synthase and 1,3- $\beta$-glucan synthase, respectively, were repressed. This finding underlined that citral can block the formation of cell wall architecture and thereby improve the sensitivity of cells to citral. In contrast, Parveen et al. [13] reported that theses two genes were dramatically induced in $S$. cerevisiae cell exposed to $\alpha$-terpinene, which in turn activated cell wall compensatory mechanism to overcome the terpinene toxicity. This discrepancy might be, to a large extent, caused by different strains, or by different antifungal mechanisms, as suggested by other reports [36, 37].

The lipophilic nature of terpenoid enables it preferentially enter into the lipid membrane, which results in the increased membrane fluidity and eventually leads to the increase of membrane permeability $[38,39]$. The expression levels of some genes involved in cell membrane-related pathways, such as inositol phosphate metabolism, fatty acid biosynthesis, biosynthesis of unsaturated fatty acids, fatty acid metabolism, and steroid biosynthesis, were changed upon citral treatment. Among them, INO1, PI4K, CDIPT, accC, FAS1, FAS2, FAB1, ERG7, ERG11, ERG6, ERG3, ERG5 were downregulated, suggesting that the integrity of cell membrane might be destroyed. Oppositely, expression of FAD6 was increased by 12.4 folds. These results were consistent with our previous study that citral could induce the disruption of membrane integrity by causing a decrease in total lipid contents of pathogen cells [8]. 


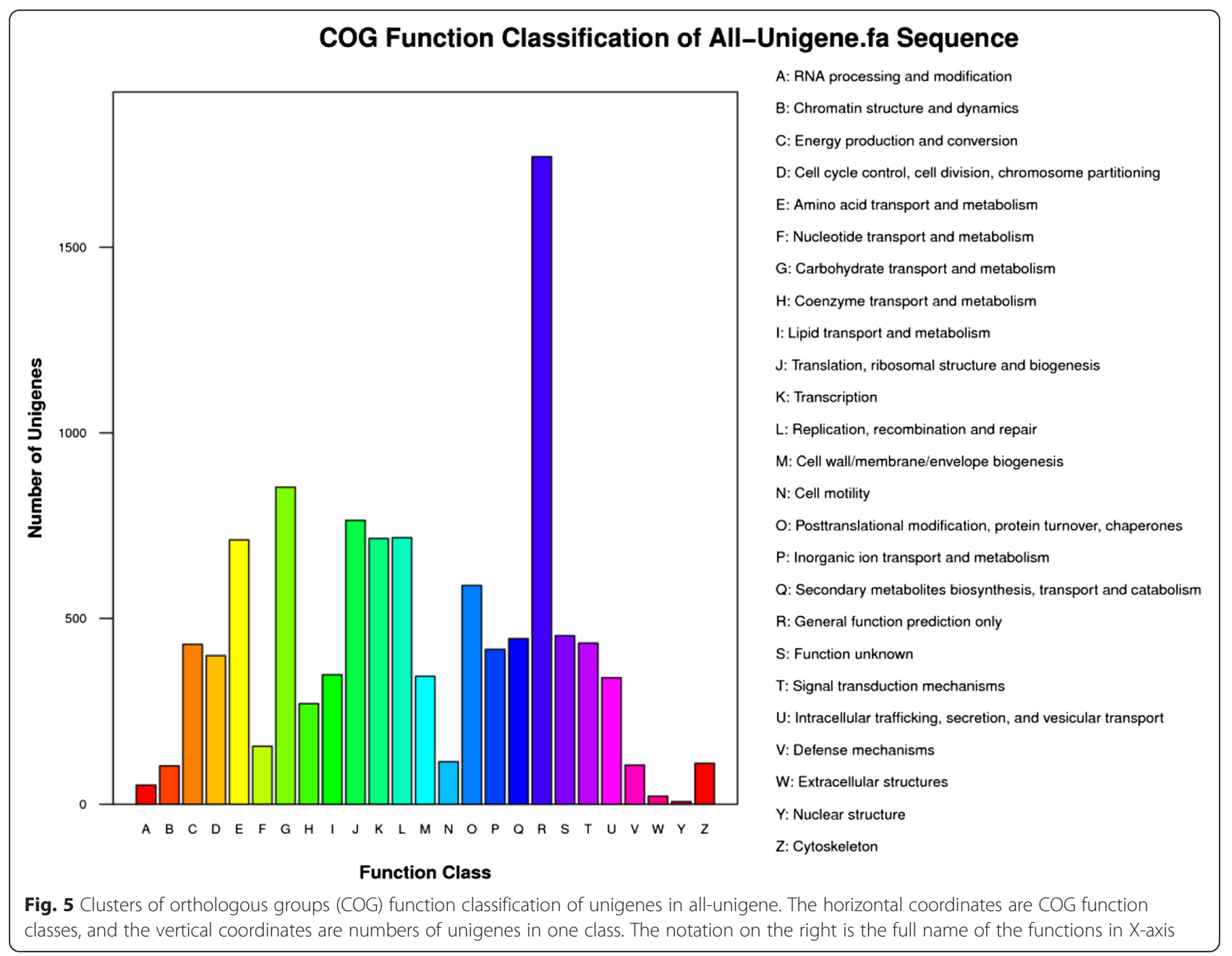

Ergosterol is one of the principal sterol components in fungal membrane. Generally, a decrease in ergosterol contents results in osmotic disturbances, disruption of cell growth and proliferation [7,39-41]. Some chemical fungicides widely used in controlling the green mold of citrus fruit, such as imazalil, prochloraz, and triflumizole, exhibited their antifungal mode by blocking the ergosterol biosynthesis, which can give rise to the disruption of cell structure and function, even to the death of cell [42-44]. Notably, the expression levels of five genes in ergosterol biosynthetic pathway encoding for lanosterol synthase (ERG7), lanosterol 14 $\alpha$-demethylase (ERG11), C-24 sterol methyl-transferase (ERG6), C-5 sterol desaturase (ERG3), and $C-22$ sterol desaturase (ERG5), were down-regulated by $2.7,2.1,2.0,2.1$ and 2.0 folds, respectively.

\section{Effect of citral on gene expression levels in ergosterol biosynthesis}

To verify the RNA-Seq results, we investigated the gene expression levels of ergosterol biosynthetic genes mentioned above. These genes serve indispensable roles in ergosterol biosynthetic pathway (Fig. 6). ERG7 is responsible for the conversion of the last acyclic sterol precursor into lanosterol, the initial cyclic intermediate in the ergosterol biosynthesis $[45,46]$. ERG11 is well-known to be the target of antifungal drugs [41, 43, 47]. ERG6 catalyzes the accumulation of fecosterol, the intermediates of ergosterol biosynthesis, and a mutated ERG6 gene makes the $C$. albicans cell loss the ability to synthesize ergosterol [48]. ERG3 introduces the C5/6 unsaturation in ergosterol biosynthesis [49]. ERG5 catalyzes the biosynthesis of ergosta-5,7,22,24(28)-trienol, a direct precursor for ergosterol biosynthesis [50]. Generally, commercial chemical fungicides, such as imazalil, ketoconazole, fluconazole, clotrimazole and dodemorph, could affect the gene expression levels of ERG11, ERG6, ERG3, and ERG5, thereby block the ergosterol biosynthesis, lead to the impairment in cell membrane functional and ultimately induce the occurrence of cell disruption [40, 41, 43, 44]. Particularly, ERG11 is the target site of some commercial chemical fungicides against $P$. digitatum $[41,43]$. 
Table 3 Enrichment pathway analysis of DEGs in $P$. digitatum

\begin{tabular}{|c|c|c|c|}
\hline Pathway & $\begin{array}{l}\text { DEGs genes with pathway } \\
\text { annotation (3232) }\end{array}$ & $\begin{array}{l}\text { All genes with pathway } \\
\text { annotation (8714) }\end{array}$ & Pathway ID \\
\hline $\mathrm{ABC}$ transporters & $64(1.98 \%)$ & $134(1.54 \%)$ & ko02010 \\
\hline Ribosome biogenesis in eukaryotes & $78(2.41 \%)$ & $171(1.96 \%)$ & ko03008 \\
\hline Alanine, aspartate and glutamate metabolism & $40(1.24 \%)$ & $83(0.95 \%)$ & ko00250 \\
\hline Starch and sucrose metabolism & $175(5.41 \%)$ & $426(4.89 \%)$ & ko00500 \\
\hline RNA degradation & $91(2.82 \%)$ & $213(2.44 \%)$ & ko03018 \\
\hline Fatty acid biosynthesis & $28(0.87 \%)$ & $62(0.71 \%)$ & ko00061 \\
\hline Non-homologous end-joining & $21(0.65 \%)$ & $45(0.52 \%)$ & ko03450 \\
\hline MAPK signaling pathway & $88(2.72 \%)$ & $221(2.54 \%)$ & ko04011 \\
\hline Amino sugar and nucleotide sugar metabolism & $98(3.03 \%)$ & $248(2.85 \%)$ & ko00520 \\
\hline Fructose and mannose metabolism & $90(2.78 \%)$ & $230(2.64 \%)$ & ko00051 \\
\hline Phosphatidylinositol signaling system & $22(0.68 \%)$ & $53(0.61 \%)$ & ko04070 \\
\hline Sulfur metabolism & $16(0.5 \%)$ & $38(0.44 \%)$ & ko00920 \\
\hline Nitrogen metabolism & $38(1.18 \%)$ & $98(1.12 \%)$ & ko00910 \\
\hline Meiosis & $80(2.48 \%)$ & $210(2.41 \%)$ & ko04113 \\
\hline Inositol phosphate metabolism & $30(0.93 \%)$ & 79 (0.91\%) & ko00562 \\
\hline Purine metabolism & $121(3.74 \%)$ & $326(3.74 \%)$ & ko00230 \\
\hline Citrate cycle (TCA cycle) & $21(0.65 \%)$ & $56(0.64 \%)$ & ko00020 \\
\hline Linoleic acid metabolism & $36(1.11 \%)$ & $97(1.11 \%)$ & ko00591 \\
\hline Glycolysis/Gluconeogenesis & $64(1.98 \%)$ & $173(1.99 \%)$ & ko00010 \\
\hline mRNA surveillance pathway & $55(1.7 \%)$ & $150(1.72 \%)$ & ko03015 \\
\hline Glutathione metabolism & $29(0.9 \%)$ & $80(0.92 \%)$ & ko00480 \\
\hline Pentose phosphate pathway & $17(0.53 \%)$ & $48(0.55 \%)$ & ko00030 \\
\hline RNA transport & $94(2.91 \%)$ & $267(3.06 \%)$ & ko03013 \\
\hline Pyrimidine metabolism & $86(2.66 \%)$ & $247(2.83 \%)$ & ko00240 \\
\hline RNA polymerase & $24(0.74 \%)$ & $73(0.84 \%)$ & ko03020 \\
\hline DNA replication & $32(0.99 \%)$ & $96(1.1 \%)$ & ko03030 \\
\hline Peroxisome & $42(1.3 \%)$ & $127(1.46 \%)$ & ko04146 \\
\hline Steroid biosynthesis & $20(0.62 \%)$ & $64(0.73 \%)$ & ko00100 \\
\hline Oxidative phosphorylation & $47(1.45 \%)$ & $144(1.65 \%)$ & ko00190 \\
\hline Biosynthesis of unsaturated fatty acids & $14(0.43 \%)$ & $53(0.61 \%)$ & ko01040 \\
\hline Fatty acid metabolism & $43(1.33 \%)$ & $147(1.69 \%)$ & ko00071 \\
\hline Aminoacyl-tRNA biosynthesis & $29(0.9 \%)$ & $109(1.25 \%)$ & ko00970 \\
\hline Plant-pathogen interaction & $1(0.03 \%)$ & $11(0.13 \%)$ & ko04626 \\
\hline Ribosome & $33(1.02 \%)$ & $224(2.57 \%)$ & ko03010 \\
\hline
\end{tabular}

As revealed by Fig. 7, the test genes followed a similar changing tendency but differed in expression levels in control and 1/2MIC citral-treated samples. The expression of ERG7 in control and 1/2MIC citral-treated samples decreased before $30 \mathrm{~min}$ of treatment, with the expression level higher in 1/2MIC citral-treated samples than that in control samples. In contrast, the gene expressions of ERG11, ERG6, ERG3, and ERG5 at $30 \mathrm{~min}$ of treatment were dramatically repressed and the expression levels in 1/2MIC citral-treated groups were significantly lower than those in control groups by 0.96 , $0.23,0.74$, and 0.36 folds, respectively (Fig. 7). These results were consistent with those of RNA-Seq analysis except the up-regulation of ERG7. After $30 \mathrm{~min}$ of exposure, the gene expressions of ERG6 and ERG3 increased first and then decreased in 1/2MIC citraltreated samples, whereas the expression levels of ERG6 and ERG3 were still lower than those of control groups. Moreover, the gene expression of ERG11 in citral-treated samples was continuously down-regulated and was 


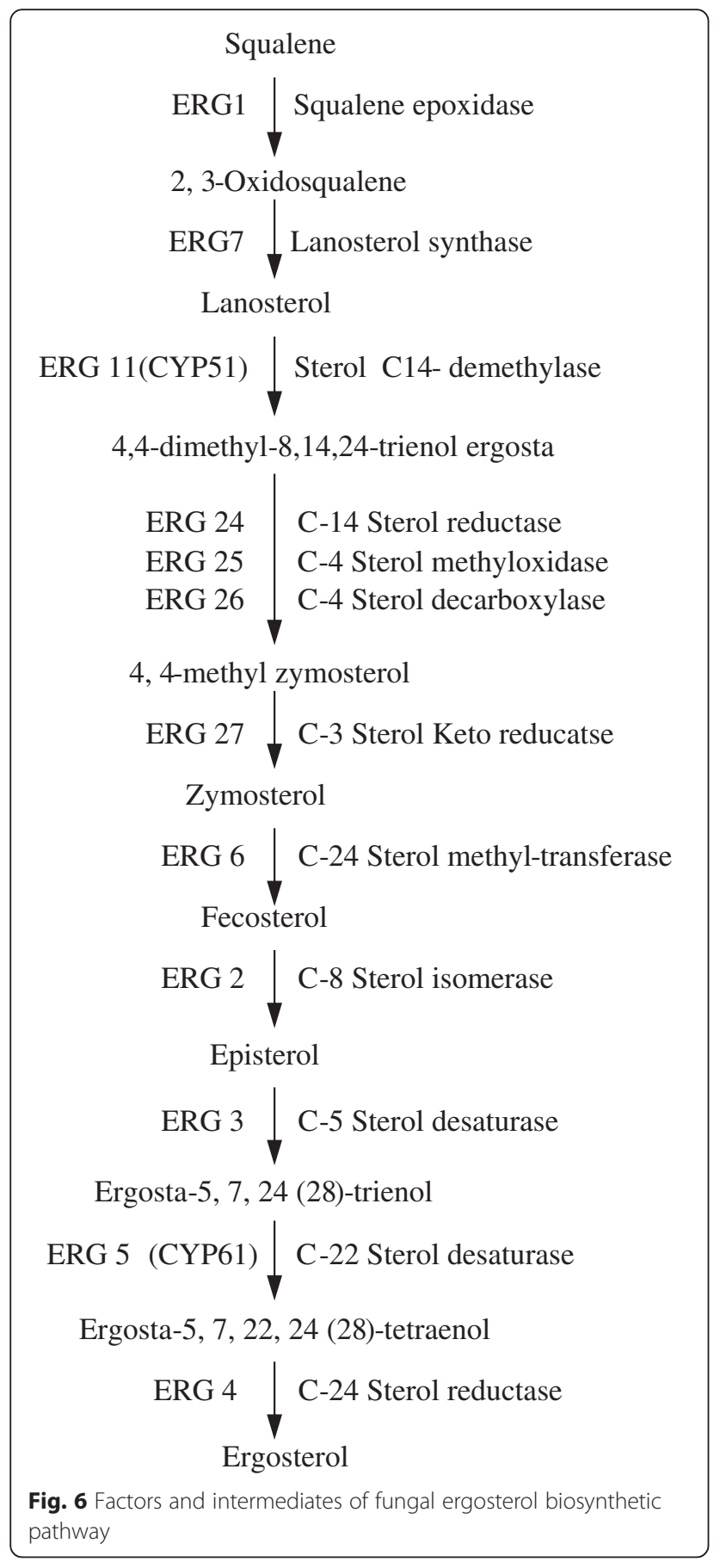

markedly lower $(P<0.05)$ than that of control samples during the entire period. In contrast, the gene expression levels of $E R G 5$ in citral-treated samples were remarkable higher $(P<0.05)$ than that in control samples at 60 min incubation. Taken these together, it can be concluded that citral can affect the expression levels of genes in ergosterol biosynthetic pathway of $P$. digitatum, and ERG11 might be an important target site of citral against $P$. digitatum.

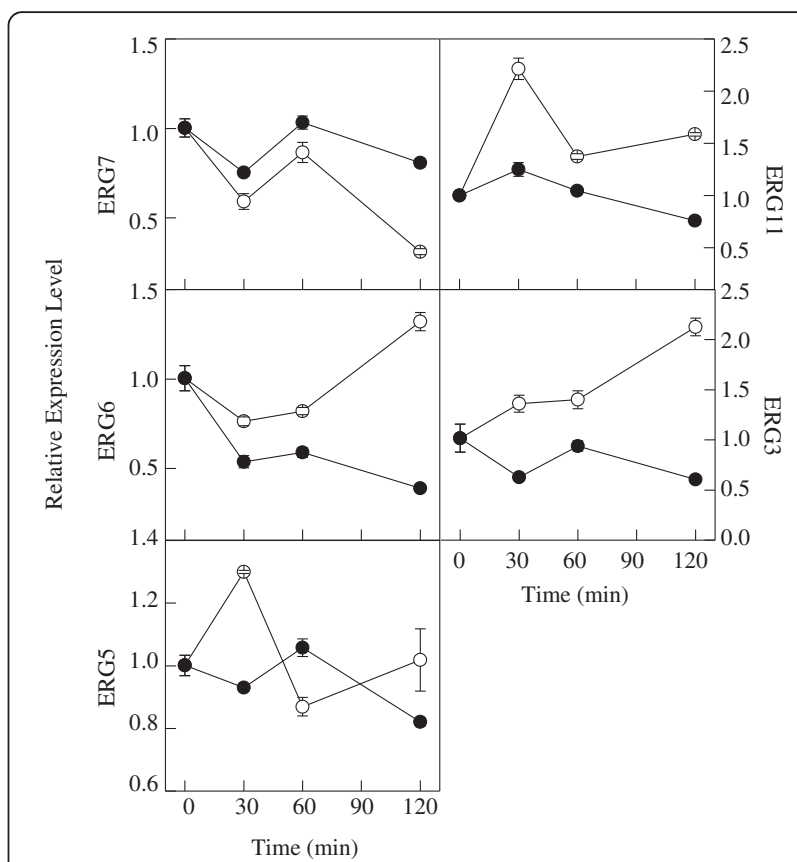

Fig. 7 Changes in the expression of ergosterol biosynthesis genes of P. digitatum mycelia treated by CK and 1/2MIC citral for 0, 30, 60 and $120 \mathrm{~min},(\mathrm{O}) \mathrm{CK} ;(\bullet) 1 / 2 \mathrm{MIC}$. Values are the mean \pm SD of three measurements

\section{Analysis of sterols composition by GC-MS}

Essential oils have been illustrated to inhibit the growth of fungi by decreasing ergosterol content, affecting membrane structure, and disrupting sterol biosynthesis $[13,39,50,51]$. Previously, we have demonstrated that total ergosterol contents in P. italicum cells were considerably decreased by citral [7]. To illustrate the effect of citral on sterols biosynthesis, we firstly determined the sterols composition of $P$. digitatum by GC-MS. The results are shown in Table 4. Nine sterols including lanosterol, ergosta-5,7,24(28)-trienol, ergosta-7,22-dienol, ergosta5,7-dienol, ergosterol, cholesterol, lanosta-7,9(11)-dienol, ergost-4,7,22-trienol, and 4 $\alpha$-methylergosta-7,24(28)dienol were tentatively identified by comparison with commercial references, the NIST $^{\mathrm{Tm}}$ database or data from literature [28, 52]. Among them, lanosterol, ergosta-5,7,24(28)-trienol, and ergosterol are the key intermediates in the ergosterol biosynthetic pathway, whereas ergosta-7,22-dienol, ergosta-5,7-dienol, and cholesterol are involved in the branched metabolic pathway related with ergosterol biosynthesis [28, 45, 46, 52]. At $30 \mathrm{~min}$ of treatment, ergosta-5,7,24(28)-trienol, the substrate for ERG5 [28, 29], was exclusively identified in 1/2MIC citral-treated group. In contrast, ergosta-5,7-dienol, a sterol in the branched metabolic pathway [28], was exclusively identified in the CK group. With prolongation of treatment, ergosta-7,22-dienol, one of the substrates for ERG3, was absent in $1 / 2 \mathrm{MIC}$ citral-treated groups. 
Table 4 The sterols composition of P. digitatum by GC-MS

\begin{tabular}{|c|c|c|c|c|c|c|c|c|c|}
\hline \multirow[t]{2}{*}{ Substance } & \multirow{2}{*}{$\begin{array}{l}\text { Rt } \\
\text { (min) }\end{array}$} & \multirow{2}{*}{$\begin{array}{l}\text { Major ions } \\
{[\mathrm{m} / \mathrm{z}]}\end{array}$} & \multicolumn{4}{|c|}{ CK group } & \multicolumn{3}{|c|}{ 1/2MIC citral-treated group } \\
\hline & & & $0 \mathrm{~min}$ & $30 \mathrm{~min}$ & $60 \mathrm{~min}$ & $120 \mathrm{~min}$ & $30 \mathrm{~min}$ & $60 \mathrm{~min}$ & $120 \mathrm{~min}$ \\
\hline Lanosta-7,9(11)-dienol & 11.975 & $498^{*}, 442,426$ & + & - & - & - & - & - & - \\
\hline Cholesterol & 12.008 & $368,329,129^{*}$ & - & - & + & - & + & - & - \\
\hline Ergosta-5,7,24(28)-trienol & 12.550 & $468,363^{*}, 337$ & - & - & - & - & + & - & - \\
\hline Ergosterol & 12.875 & $378,363^{*}, 337$ & + & + & + & + & + & + & + \\
\hline Ergosta-7,22-dienol & 13.042 & $470,343^{*}, 255$ & - & + & + & + & + & + & - \\
\hline Ergosta-5,7-dienol & 13.492 & $380,365^{*}, 339$ & - & + & - & - & - & - & - \\
\hline ergost-4,7,22-trienol & 13.717 & $482,392,377^{*}$ & - & + & - & + & - & - & - \\
\hline Lanosterol & 13.908 & $498,393^{*}, 241$ & + & + & + & + & + & + & + \\
\hline 4a-methylergosta-7,24(28)-dienol & 14.517 & $497,407^{*}, 207$ & + & + & + & + & + & + & + \\
\hline
\end{tabular}

Rt retention time; *: Base peak; ' +': detected; ' - ': not detected

Meanwhile, lanosterol and ergosterol were present in all test samples. These results indicate that the target site of citral against $P$. digitatum might be the upstream genes before $E R G$ 3, which are consistent with the gene expression results.

\section{Ergosterol and lanosterol contents}

To confirm the results of GC-MS analysis and to illustrate the effect of citral on ergosterol biosynthesis further, we determined the lanosterol and ergosterol contents of $P$. digitatum by HPLC-UV. The chromatograms for the ergosterol standard, the ergosterol in control and 1/2MIC citral treated samples were presented in Fig. 8a, b and c, respectively. The ergosterol contents of $P$. digitatum cells treated with citral continuously decreased throughout the entire period, whereas those in the untreated cells remained stable (Fig. 8d). The ergosterol content of $P$. digitatum cells incubated with $1 / 2 \mathrm{MIC}$ of citral for $30 \mathrm{~min}$ was $4.08 \pm 0.11 \mathrm{mg} / \mathrm{g}$ DW, which was significantly lower than that of the control $(4.90 \pm 0.29 \mathrm{mg} / \mathrm{g} \mathrm{DW})$. This difference became more evident with the increasing of exposure time. The ergosterol contents in treatment cells was $2.80 \pm 0.09 \mathrm{mg} / \mathrm{g}$ DW at
$120 \mathrm{~min}$ of exposure, as compared to $5.22 \pm 0.66 \mathrm{mg} / \mathrm{g}$ DW in control cells.

The chromatograms for the lanosterol standard, the lanosterol in control and $1 / 2 \mathrm{MIC}$ citral treated samples were presented in Fig. 9a, b and c, respectively. The lanosterol content in control samples did not alter significantly during the entire period (Fig. 9d). Likely, the lanosterol content in citral-treated samples did not alter significantly at the initial $30 \mathrm{~min}$ (Fig. 9d). After $60 \mathrm{~min}$ of exposure, the lanosterol exclusively accumulated in citral-treated samples, whose content reached $2.56 \pm 0.15 \mathrm{mg} / \mathrm{g}$ DW and was significantly higher than that of the control $(1.74 \pm 0.14 \mathrm{mg} / \mathrm{g} D W)$. This result, together with the decreased ergosterol content in citraltreated samples, indicates that the ergosterol biosynthesis pathway in $P$. digitatum was partially blocked by citral exposure. This blocking was commonly caused by the antifungal substances used in controlling postharvest diseases [53, 54].

The ergosterol and lanosterol contents in 1/2MIC citral-treated $P$. digitatum cells correspond well with the transcriptional regulation of ERG7, ERG11, ERG6, ERG3, and $E R G 5$ genes. After the initial addition of citral, the
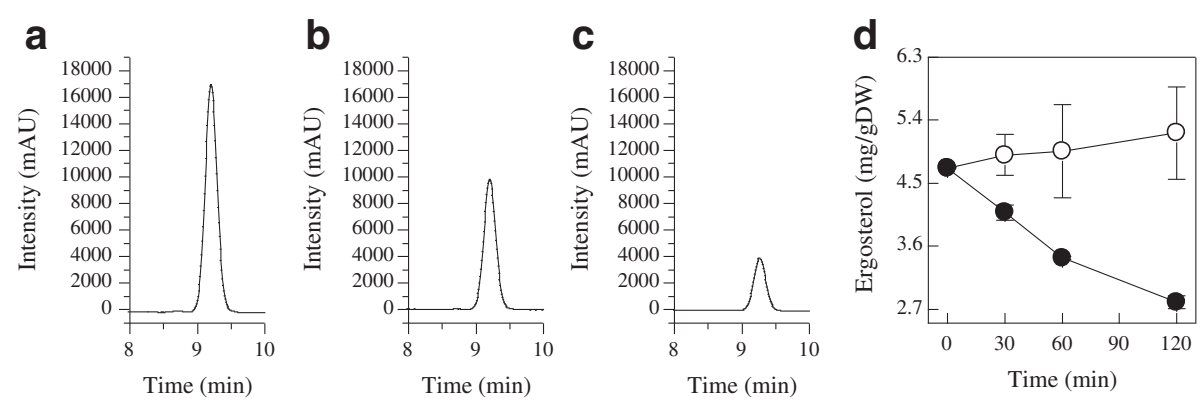

Fig. $8 \mathrm{HPLC}$ analysis of ergosterol in control and 1/2MIC citral treated samples. a: The ergosterol standard (with a retention time of 9.376 min); b: The ergosterol in control samples (with a retention time of $9.205 \mathrm{~min}$ ); c: The ergosterol in 1/2MIC citral treated samples (with a retention time of $9.269 \mathrm{~min})$; d: Total ergosterol contents in control (o) and 1/2MIC citral treated $(\bullet) P$. digitatum cells, and values are the mean \pm SD of three measurements 

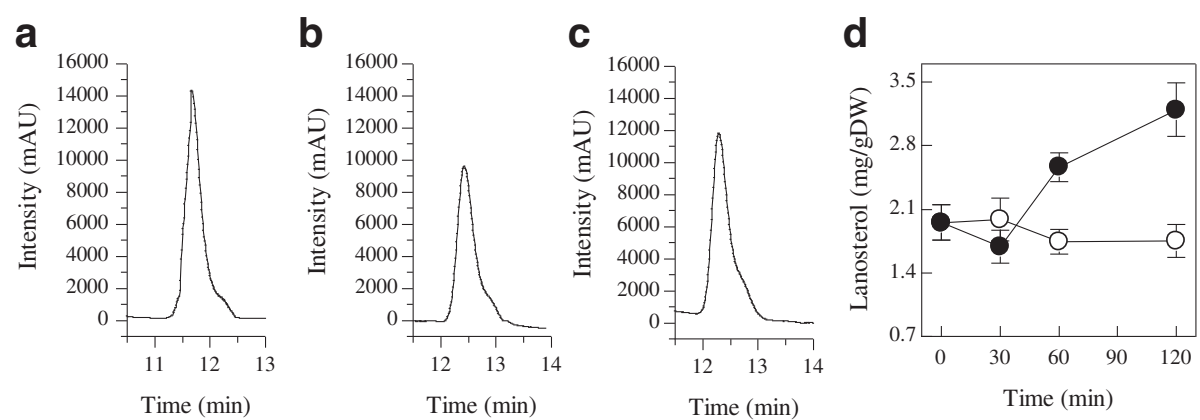

Fig. 9 HPLC analysis of lanosterol in control and 1/2MIC citral treated samples. a: The lanosterol standard (with a retention time of 11.669 min); b: The lanosterol in control samples (with a retention time of $12.426 \mathrm{~min}$ ); $\mathbf{c}$ : The lanosterol in 1/2MIC citral treated samples (with a retention time of $12.288 \mathrm{~min}$ ); $\mathbf{d}$ : Total lanosterol contents in control (o) and 1/2MIC citral treated $(\bullet)$ P. digitatum cells, and values are the mean \pm SD of three measurements

gene expressions of ERG11, ERG6, ERG3, and ERG5 were partially inhibited and these led to the decrease in total ergosterol content before $30 \mathrm{~min}$ of exposure. Correspondingly, the absence of ergosterol might induce the gene expression of ERG7 at this time, as convinced by the up-regulation of this gene and the accumulation of lanosterol content. The gene expressions of ERG7 in both groups have the same changing tendency after $60 \mathrm{~min}$ of exposure, but the expression levels in 1/2MIC citral-treated samples were significantly higher $(P<0.05)$ than those in control group. This up regulation, together with the reduction of ergosterol content, might stimulate the gene expressions of ERG6, ERG3 and ERG5 to provide more ergosterol to meet the demand of cells, which is thought to be a general response to decreased ergosterol levels [54]. This regulatory manner is similar to a previous finding that described in S. cerevisiae cells exposed to $\alpha$-terpinene [13]. Nevertheless, the gene expressions of ERG6 and ERG3 in 1/2MIC group were still lower than the control groups, which were supposed to contribute a lot to the inhibition of ergosterol biosynthesis, as illustrated by other documents [41, 55-57]. The gene expression of ERG5 in 1/2MIC group was lower than that in the CK group at $120 \mathrm{~min}$ of treatment, which might be caused by the reduction in its precursor (ergosta-5,7,24(28)-trienol). Interestingly, the expression levels of ERG11 continuously declined in 1/2MIC citraltreated groups and were always lower than those of CK group. Considering that the down-regulation of ERG11 can block the ergosterol biosynthesis and lead to the decrease of ergosterol content to inhibit the growth of fungi $[43,47]$, our present finding implies that $E R G 11$ is a critical target of citral against $P$. digitatum.

\section{Conclusions}

In conclusion, our present research revealed that the global gene expressions involved in many important pathways in $P$. digitatum hyphae, including $\mathrm{ABC}$ transport, steroid biosynthesis, amino sugar and nucleotide sugar metabolism, starch and sucrose metabolism, TCA cycle, oxidative phosphorylation, RNA degradation, and ribosome, can be greatly affected by citral exposure. RTFQ-PCR verified that citral can affect the expression level of five genes (ERG7, ERG11, ERG6, ERG3 and $E R G 5)$ in ergosterol biosynthetic pathway of $P$. digitatum, showing that ERG11 is a critical targeted gene. In addition, the ergosterol and lanosterol contents in citraltreated samples correspond well with the coordinated regulation of these five genes and GC-MS results. These results suggest that citral could exhibit its antifungal activity against the mycelial growth of $P$. digitatum by disrupting ergosterol biosynthesis.

\section{Additional files}

Additional file 1: Table S1. Annotation of all Penicillium digitatum unigenes. (XLS $11070 \mathrm{~kb}$ )

Additional file 2: Table S2. The sequencing data of all Penicillium digitatum CDS mapped to the protein database or predicted. (DOC $17505 \mathrm{~kb}$ )

Additional file 3: Table S3. The differentially expressed genes in untreated Penicillium digitatum (CK30) and citral-treated $P$. digitatum (T30) $(P<0.05)$. (XLS $4848 \mathrm{~kb})$

\begin{abstract}
Abbreviations
MIC, minimum inhibitory concentration; PDA, potato dextrose agar; PDB, potato dextrose broth; DEGs, differentially expressed genes; FPKM, fragments per Kb million fragments; FDR, false discovery rate; RTFQ-PCR, real-time fluorescence quantitative PCR; RIN, RNA integrated number; CDS, coding sequence; NR, non-redundant protein; NT, non-redundant nucleotide sequence; KEGG, Kyoto Encyclopedia of Genes and Genomes; COG, clusters of orthologous groups of proteins; GO, gene ontology; NCBI, National Center for Biotechnology Information; GC-MS, gas chromatography-mass spectrometry; HPLC, high-performance liquid chromatography; MSTFA, $\mathrm{N}$-methyl-N-trimethylsilyltrifluoroacetamide; TSIM, N-trimethylsilylimidazole; MRD, multi-drug resistance; MRP, Multi-drug resistance-associated protein; PDR, Pleiotropic drug resistance; $1 / 2 \mathrm{MIC}$, Half of minimum inhibitory concentration
\end{abstract}

Acknowledgements Not applicable. 


\section{Funding}

This study was supported by the National Natural Science Foundation of China (Nos.31572172 and 31271964) and Research Foundation of Education Bureau of Hunan Province (Nos.15A 181 and 12B126)

\section{Availability of data and materials}

The datasets generated during and/or analyzed during the current study are not publicly available due to the follow-up study about these datasets is under way but are available from the corresponding author on reasonable request.

\section{Authors' contributions}

NT designed research; QO performed research; NT and QO analyzed data; and QO, NT and GJ wrote the paper. All authors read and approved the final manuscript.

\section{Competing interests}

The authors declare that they have no competing interests.

\section{Consent for publication}

Not applicable.

\section{Ethics approval and consent to participate}

Not applicable.

Received: 15 February 2016 Accepted: 18 July 2016

Published online: 11 August 2016

\section{References}

1. Smilanick JL, Mansour MF, Gabler FM, Sorenson D. Control of citrus postharvest green mold and sour rot by potassium sorbate combined with heat and fungicides. Postharvest Biol Tec. 2008;47:226-38.

2. Macarisin D, Cohen L, Eick A, Rafael G, Belausov E, Wisniewski M, Droby S. Penicillium digitatum suppresses production of hydrogen peroxide in host tissue during infection of citrus fruit. Phytopathology. 2007:97:1491-500.

3. Shao $X$, Cheng S, Wang H, Yu D, Mungai $C$. The possible mechanism of antifungal action of tea tree oil on Botrytis cinerea. J Appl Microbiol. 2013;114:1642-9.

4. Wuryatmo E, Able AJ, Ford CM, Scott ES. Effect of volatile citral on the development of blue mould, green mould and sour rot on navel orange. Australas Plant Path. 2014;43:403-11.

5. Droby S, Eick A, Macarisin D, Cohen L, Rafael G, Stange R, McColumb G, Dudaic N, Nasserd A, Wisniewski M, et al. Role of citrus volatiles in host recognition, germination and growth of Penicillium digitatum and Penicillium italicum. Postharvest Biol Tec. 2008;49:386-96.

6. Wuryatmo E, Klieber A, Scott ES. Inhibition of citrus postharvest pathogens by vapor of citral and related compounds in culture. J Agr Food Chem. 2003:51:2637-40.

7. Tao NG, OuYang QL, Jia L. Citral inhibits mycelial growth of Penicillium italicum by a membrane damage mechanism. Food Control. 2014;41:116-21.

8. Zhou HE, Tao NG, Jia L. Antifungal activity of citral, octanal and a-terpineol against Geotrichum citri-aurantii. Food Control. 2014;37:277-83.

9. Fan F, Tao NG, Jia L, He XL. Use of citral incorporated in postharvest wax of citrus fruit as a botanical fungicide against Penicillium digitatum. Postharvest Biol Tec. 2014:90:52-5.

10. Bajpai VK, Sharma A, Baek KH. Antibacterial mode of action of Cudrania tricuspidata fruit essential oil, affecting membrane permeability and surface characteristics of food-borne pathogens. Food Control. 2013;32:582-90.

11. Ultee A, Bennik MHJ, Moezelaar R. The phenolic hydroxyl group of carvacrol is essential for action against the food-borne pathogen Bacillus cereus. Appl Environ Microb. 2002;68:1561-8.

12. Zheng SJ, Jing GX, Wang X, Ouyang QL, Jia L, Tao NG. Citral exerts its antifungal activity against Penicillium digitatum by affecting the mitochondrial morphology and function. Food Chem. 2015;158:76-81.

13. Parveen M, Hasan MK, Takahashi J, Murata Y, Kitagawa E, Kodama O, Iwahashi H. Response of Saccharomyces cerevisiae to a monoterpene: evaluation of antifungal potential by DNA microarray analysis. J Antimicrob Chemother. 2004:54:46-55.

14. Rao A, Zhang YQ, Muend S, Rao R. Mechanism of antifungal activity of terpenoid phenols resembles calcium stress and inhibition of the TOR pathway. Antimicrob Agents Chemother. 2010;54:5062-9.
15. Yu L, Guo N, Yang Y, Wu XP, Meng RZ, Fan JW, Wang XL, Liu JB, Deng XM. Microarray analysis of $\mathrm{p}$-anisaldehyde-induced transcriptome of Saccharomyces cerevisiae. J Ind Microbiol Biot. 2010;37:313-22.

16. Bi X, Guo N, Jin J, Liu J, Feng H, Shi J, Xiang H, Wu X, Dong J, Hu H, et al. The global gene expression profile of the model fungus Saccharomyces cerevisiae induced by thymol. J Appl Microbiol. 2010;108:712-22.

17. Wang LK, Feng ZX, Wang X, Wang XW, Zhang XG. DEGseq: an R package for identifying differentially expressed genes from RNA-seq data. Bioinformatics. 2010;26:136-8.

18. Van Verk MC, Hickman R, Pieterse CM, Van Wees SC. RNA-Seq: revelation of the messengers. Trends Plant Sci. 2013;18:175-9.

19. Hershkovitz V, Sela N, Taha-Salaime L, Liu J, Rafael G, Kessler C, Aly R, Levy M, Wisniewski M, Droby S. De-novo assembly and characterization of the transcriptome of Metschnikowia fructicola reveals differences in gene expression following interaction with Penicillium digitatum and grapefruit peel. BMC Genomics. 2013;14:168

20. Aritua V, Achor D, Gmitter FG, Albrigo G, Wang N. Transcriptional and microscopic analyses of citrus stem and root responses to Candidatus Liberibacter asiaticus infection. PLoS One. 2013;8,

21. Liu P, Cheng YJ, Yang M, Liu YJ, Chen K, Long CA, Deng XX. Mechanisms of action for 2-phenylethanol isolated from Kloeckera apiculata in control of Penicillium molds of citrus fruits. BMC Microbiol. 2014;14:242.

22. Liu B, Jiang GF, Zhang YF, Li JL, Li XJ, Yue JS, Chen F, Liu HQ, Li HJ, Zhu SP. Analysis of transcriptome differences between resistant and susceptible strains of the citrus red mite Panonychus citri (Acari: Tetranychidae). PLoS One. 2011;6:e28516.

23. Grabherr MG, Haas BJ, Yassour M, Levin JZ, Thompson DA, Amit I, Adiconis X, Fan L, Raychowdhury R, Zeng QD, et al. Full-length transcriptome assembly from RNA-Seq data without a reference genome. Nat Biotechnol. 2011;29:644-52.

24. Pertea G, Huang X, Liang F, Antonescu V, Sultana R, Karamycheva S, Lee $Y$ White J, Cheung F, Parvizi B, et al. TIGR Gene Indices clustering tools (TGICL), a software system for fast clustering of large EST datasets. Bioinformatics. 2003;19:651-2.

25. Iseli C, Jongeneel CV, Bucher P. ESTScan: a program for detecting, evaluating, and reconstructing potential coding regions in EST sequences. Proc Int Conf Intell Syst Mol Biol. 1999:99:138-48.

26. Audic S, Claverie JM. The significance of digital gene expression profiles Genome Res. 1997:7:986-95.

27. Livak KJ, Schmittgen TD. Analysis of relative gene expression data using Real-Time quantitative PCR and the $2^{-\Delta \Delta C}$ method. Methods. 2001;25:402-8.

28. Müller C, Staudacher V, Krauss J, Giera M, Bracher F. A convenient cellular assay for the identification of the molecular target of ergosterol biosynthesis inhibitors and quantification of their effects on total ergosterol biosynthesis. Steroids. 2013;78:483-93.

29. Alcazar-Fuoli L, Mellado E, Garcia-Effron G, Lopez JF, Grimalt JO, Cuenca-Estrella JM, Rodriguez-Tudela JL. Ergosterol biosynthesis pathway in Aspergillus fumigatus. Steroids. 2008;73:339-47.

30. Legay G, Marouf E, Berger D, Neuhaus JM, Mauch-Mani B, Slaughter A. Identification of genes expressed during the compatible interaction of grapevine with Plasmopara viticola through suppression subtractive hybridization (SSH). Eur J Plant Pathol. 2011;129:281-301.

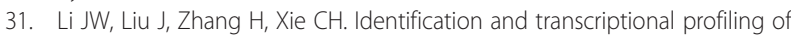
differentially expressed genes associated with resistance to Pseudoperonospora cubensis in cucumber. Plant Cell Rep. 2011;30:345-57.

32. Zhang L, Zhang Y, Zhou YM, An S, Zhou YX, Cheng J. Response of gene expression in Saccharomyces cerevisiae to amphotericin B and nystatin measured by microarrays. J Antimicrob Chemother. 2002;49:905-15.

33. Gasch AP, Spellman PT, Kao CM, Carmel-Harel O, Eisen MB, Storz G, Botstein D, Brown PO. Genomic expression programs in the response of yeast cells to environmental changes. Mol Biol Cell. 2002;11:4241-57.

34. Nakaune R, Adachi K, Nawata O, Tomiyama M, Akutsu K, Hibi T. A novel ATP-binding cassette transporter involved in multidrug resistance in the phytopathogenic fungus Penicillium digitatum. Appl Environ Microb. 1998:64:3983-8

35. Paumi CM, Chuk M, Snider J, Stagljar I, Michaelis S. ABC transporters in Saccharomyces cerevisiae and their interactors: new technology advances the biology of the ABCC (MRP) subfamily. Microbiol Mol Biol R. 2009;73:577-93.

36. Bakkali F, Averbeck S, Averbeck D, Idaomar M. Biological effects of essential oils-a review. Food Chem Toxicol. 2008:46:446-75.

37. Kalemba D, Kunicka A. Antibacterial and antifungal properties of essential oils. Curr MedChem. 2003;10:813-29. 
38. Burt S. Essential oils: their antibacterial properties and potential applications in foods - a review. Int J Food Microbiol. 2004;94:223-53.

39. Khan A, Ahmad A, Akhtar F, Yousuf S, Xess I, Khan LA, Manzoor N. Ocimum sanctum essential oil and its active principles exert their antifungal activity by disrupting ergosterol biosynthesis and membrane integrity. Res Microbiol. 2010;161:816-23.

40. Onyewu C, Blankenship JR, Del Poeta M, Heitman J. Ergosterol biosynthesis inhibitors become fungicidal when combined with calcineurin inhibitors against Candida albicans, Candida glabrata, and Candida krusei. Antimicrob Agents Chemother. 2003;47:956-64

41. Sun XP, Wang JY, Feng D, Ma ZH, Li HY. PdCYP51B, a new putative sterol 14a-demethylase gene of Penicillium digitatum involved in resistance to imazalil and other fungicides inhibiting ergosterol synthesis. Appl Microbiol Biot. 2011;91:1107-19.

42. Hamamoto H, Hasegawa K, Nakaune R, Lee YJ, Makizumi Y, Akutsu K, Hibi T. Tandem repeat of a transcriptional enhancer upstream of the sterol $14 \mathrm{a}-$ demethylase gene (CYP51) in Penicillium digitatum. Appl Environ Microb. 2000;66:3421-6

43. Liu J, Yuan YZ, Wu Z, Li N, Chen YL, Qin TT, Geng HH, Xiong L, Liu D. A novel sterol regulatory element-binding protein gene (sreA) identified in Penicillium digitatum is required for prochloraz resistance, full virulence and erg11 (cyp51) regulation. PLoS One. 2015;10:e0117115.

44. Wang JL, Yu JH, Liu J, Yuan YZ, Li N, He MQ, Qi T, Hui G, Li X, Liu DL. Novel mutations in CYP51B from Penicillium digitatum involved in prochloraz resistance. J Microbiol. 2014;52:762-70.

45. Nes WD. Biosynthesis of cholesterol and other sterols. Chem Rev. 2011;111:6423-51

46. Nes WD, Hanners PK, Parish EJ. Control of fungal sterol C-24 transalkylation: importance to developmental regulation. Biochem Biophys Res Commun. 1986;139:410-5.

47. Liu J, Wang SQ, Qin TT, Li N, Niu YH, Li DD, Yuan YZ, Geng H, Xiong L, Liu $D$. Whole transcriptome analysis of Penicillium digitatum strains treatmented with prochloraz reveals their drug-resistant mechanisms. BMC Genomics. 2015;16:1.

48. Jensen-Pergakes KL, Kennedy MA, Lees ND, Barbuch R, Koegel C, Bard M. Sequencing, disruption, and characterization of the Candida albicans sterol methyltransferase (ERG6) gene: drug susceptibility studies in erg6 Mutants. Antimicrob Agents Chemother. 1998;42:1160-7.

49. Veen M, Stahl U, Lang C. Combined overexpression of genes of the ergosterol biosynthetic pathway leads to accumulation of sterols in Saccharomyces cerevisiae. FEMS Yeast Res. 2003;4:87-95.

50. da Silva BN, Nakassugi LP, Oliveira JFP, Kohiyama CY, Mossini SAG, Grespan R, Nerilo SB, Mallmann CA, Filho BAA, Machinski Jr M. Antifungal activity and inhibition of fumonisin production by Rosmarinus officinalis $\mathrm{L}$. essential oil in Fusarium verticillioides (Sacc.) Nirenberg. Food Chem. 2015;166:330-6.

51. Tian J, Wang YZ, Zeng H, Li ZY, Zhang P, Tessema A, Peng X. Efficacy and possible mechanisms of perillaldehyde in control of Aspergillus niger causing grape decay. Int J Food Microbiol. 2015;202:27-34

52. Xu X, Gao Y, Sun L. Free and esterified triterpene alcohol composition of bee pollen from different botanical origins. Food Res Int. 2012;48:650-6.

53. Chang WQ, Zhang M, Li Y, Li XB, Gao YH, Xie ZY, Lou HX. Lichen endophyte derived pyridoxatin inactivates Candida growth by interfering with ergosterol biosynthesis. Biochim Biophys Acta. 2015;1850:1762-71.

54. Njombolwana NS, Erasmus A, Fourie PH. Evaluation of curative and protective control of Penicillium digitatum following imazalil application in wax coating. Postharvest Biol Tec. 2013;77:102-10.

55. Kagan IA, Michel A, Prause A, Scheffler BE, Pace P, Duke SO. Gene transcription profiles of Saccharomyces cerevisiae after treatment with plant protection fungicides that inhibit ergosterol biosynthesis. Pestic Biochem Phys. 2005;82:133-53.

56. Sanglard D, Ischer F, Parkinson T, Falconer D, Bille J. Candida albicans mutations in the ergosterol biosynthetic pathway and resistance to several antifungal agents. Antimicrob Agents Chemother. 2003;47:2404-12.

57. Khodavandi A, Alizadeh F, Vanda NA, Karimi G, Chong PP. Possible mechanisms of the antifungal activity of fluconazole in combination with terbinafine against Candida albicans. Pharm Biol. 2014;52:1505-9.

\section{Submit your next manuscript to BioMed Central and we will help you at every step:}

- We accept pre-submission inquiries

- Our selector tool helps you to find the most relevant journal

- We provide round the clock customer support

- Convenient online submission

- Thorough peer review

- Inclusion in PubMed and all major indexing services

- Maximum visibility for your research

Submit your manuscript at www.biomedcentral.com/submit
() BioMed Central 